\title{
Why should we screen for perinatal depression? Ten reasons to do it
}

\author{
Ana Telma Pereira1, Maria João Soares', Sandra Bos', Mariana Marques², Berta Maia², José Valente', \\ Vasco Nogueira', Carolina Roque', Nuno Madeira', Maria Helena Pinto de Azevedo', and António Macedo
}

\begin{abstract}
In this paper we review some of the best available evidence to argue that screening for perinatal depression should be systematically conducted since pregnancy. Our view is organized in ten topics: (1) perinatal depression high prevalence; (2) its potential negative consequences, including maternal, conjugal, foetal, infantile, and child effects; (3) its under-detection and treatment; (4) its stigma; (5) the professionals and women misconceptions related to perinatal depression; (6) the availability of valid and short self-report screening instruments for perinatal depression and (7) their acceptability; (8) the increase in recognition, diagnosis, and treatment rates in comparison with routine practice; (9) the opportunity, given the large number of contacts that women have with health professionals in the perinatal period; and (10) perinatal depression screening potential cost-effectiveness.
\end{abstract}

Keywords: Screening, Perinatal depression, Pregnancy, Postpartum, Ten reasons.

\author{
'Psychological Medicine Department, Faculty of Medicine, University of \\ Coimbra, Portugal \\ ${ }^{2}$ Miguel Torga Higher Institute, Coimbra, Portugal \\ ${ }^{3}$ High Institute of Social Service, Porto, Portugal
}

Citation: Pereira et al. Why should we screen for perinatal depression? Ten reasons to do it. IJCNMH 2014; 1:10

Received: 02 Jan 2014; Accepted: 13 May 2014; Published: 06 Jun 2014

Correspondence: Ana Telma Pereira

Psychological Medicine Department, Faculty of Medicine, University of Coimbra

Rua Larga, 3004-504, Coimbra, Portugal

Email address: apereira@fmed.uc.pt 


\section{Introduction}

Over the last decades, the scientific literature has accumulated to show that perinatal depression should be considered a major public health problem [1]. In developed countries as the UK, Australia, New Zealand, Canada and the US, systematic screening programs for perinatal depression are already being implemented [2-4]. Thus, screening and case identification strategies have been advocated, but have also attracted substantial controversy [5]. In the following paragraphs we review the best available evidence to defend perinatal depression screening, that is, ten reasons to detect and treat perinatal depression since pregnancy.

\section{Ten reasons to screen for perinatal depression}

\section{First}

We should screen for perinatal depression because of its high prevalence: although antenatal depression (AD) is less well documented than postpartum depression (PPD), it is at least as common as PPD and for almost half of women it may continue into the postpartum period (e.g. [6, 7]). Furthermore, $\mathrm{AD}$ is one of the most consistent risk factors for PPD [8]. The best point prevalence estimates of major depression at different times during pregnancy range from $3.1 \%$ to $4.9 \%$; when minor depression is included, the point prevalence range rises from $8.5 \%$ to $11.0 \%$. In the postpartum these figures range from $1.0 \%$ to $5.9 \%$ and $6.5 \%$ to $12.9 \%$, respectively [9]. In a recent and rigorous study from our team, the prevalence of depressive disorders at pregnancy (third trimester) was of $2.3 \%$ according to ICD10 and of $1.3 \%$ according to DSM-IV. Regarding period prevalence from delivery to the twelfth month postpartum it was of $11.0 \% / C I D-10$ and of $8.9 \% / D S M-I V ~[10]$. While estimates of point prevalence of depression at six months are similar to those observed at other times in childbearing years $[9,11]$, the incidence of depression is higher in the first five weeks postpartum, probably due to the stressful effect of childbirth [11]. Additionally, in women with significant preexisting mood disorders, the risk of perinatal relapse is higher than in any other period [12].

\section{Second}

Because of the potential negative consequences of $\mathrm{AD}$, including maternal, fetal, infantile, and child effects. For women, these include non-compliance with prenatal care and with healthy life styles [13], spontaneous abortion [14], preeclampsia, [15] and complicated deliveries [16].

$\mathrm{AD}$ has child immediate effects associated with increased morbidity and mortality in the infant, including preterm delivery and lower birth weight [17]. As examples of the long-term adverse effects of $\mathrm{AD}$, we can mention more difficult infant temperament $[18,19]$, behavioral and emotional problems [20], hyperactivity, poor social skills [21] and sleep problems [22] in childhood, and higher risk of criminality [23] and depression in adolescence [24].
Also very well documented is the negative impact of PPD on the entire family [25], from the early difficulties in mother-infant relationship [26], and maladaptive caretaking behaviors and parenting [27], to the infant, toddler [28], preadolescent [29] and adolescence [30] social, emotional, and behavioral development. Mother-child interactions in the presence of PPD may be characterized simultaneously by hostility and unresponsiveness [31, 32]. Stein et al. [33] proposed that a woman's self-preoccupation and rumination may be a critical process in understanding the effects of PPD on responsive parenting.

Furthermore, women with depressive symptoms are less likely to attend well-child visits, complete immunizations, use home safety devices and car seats, use recommended practices in putting infants to sleep, and setting safe water heater temperature levels [34].

Recent longitudinal studies showed that maternal depressive symptoms experienced during the first six months postpartum are associated with internalizing and externalizing psychopathology from early childhood to adolescence $[35,36]$.

The literature examining the effects of PPD on child cognitive development is quite well established, with qualitative reviews converging in their conclusions. It is consensual that PPD predicts poorer language and IQ development in children and that this effect is found across childhood and adolescence [28, 37-39].

Because of a depressed mother's maladaptive caretaking behaviors, her infant's health may suffer. There is good evidence that PPD is associated with poorer child cardiovascular functioning [40], gastrointestinal infections and lower respiratory tract infections [41]. Finally, other studies provide evidence that PPD affects child growth [42, 43].

It is also important to mention that PPD undermines marital relationships, being high the association between PPD and depression in the partner [25].

In summary, like major depression that occurs at other times in a woman's life, PPD creates personal suffering and diminishes a woman's ability to function effectively in many spheres of her life. What is different is that postpartum women have major responsibility as they are caring of a young infant, and ongoing depression interferes with parenting and is associated with a variety of negative child outcomes at both short and long term [4].

\section{Third}

Because of the dramatic under-detection and treatment of perinatal depression. Approximately $75 \%$ of the cases of this treatable condition are not identified by professionals (eg. $[44,45]$ ) and without screening programs, only $10 \%$ of women are treated [46]. This constitutes one of the most important and costly public health problems concerning perinatal women [47].

\section{Fourth}

The majority of women with PPD symptoms do not seek 
help from any source [48]. Help-seeking behavior for PPD is influenced by a variety of factors, including recognition of the problem, available resources, adequate social support, perceived stigma, and guilty for suffering during a period that is supposed to be happy and of fulfillment $[49,50]$.

\section{Fifth}

Because of professionals' [51, 52] and womens' [53] misconceptions about some depressive features. Symptoms, such as disturbed sleep, appetite, energy and interest level, which are true symptoms of depression may be confused with symptoms normally associated with pregnancy and postpartum [54].

\section{Sixth}

The availability of valid, reliable and economical screening tools. The most widely used screening questionnaire for PPD is the Edinburgh Postpartum Depression Scale (EPDS) [55]. It has only 10 items and it has been translated and validated into many languages. The most important limitation of the EPDS is the fact that although it was specifically designed to screen for PPD, all items are similar to those from general depression scales, meaning that it does not include items about the context of a woman's experience as a new mother. Although perinatal depression symptomatology is not specific, it is influenced by the particular situation of being a mother of a newborn [56] and some authors have reported differences between perinatal depressive episodes and those that occur in other periods, such as, more anxious features, guilty, emotional lability, irritability, and concentration/decision-making difficulties $[54,57]$; irrational worries about the well-being of the infant; and obsessional thoughts of harming themselves or their infants are not uncommon [58]. Gibson et al. [59] systematically reviewed the published evidence on EPDS validity for detecting PPD and AD. Sensitivity, specificity, and positive predictive values (PPV) of cut-off points showed marked heterogeneity between studies. Sensitivity results ranged from 34 to $100 \%$, specificity from 44 to $100 \%$ and PPV from 9 to $64 \%$.

Although NICE guidance published in 2007 [60] recommended the use of the Whooley questions (depressed feelings and loss of interest in activities; if "yes" to either question, a third question about the need for help), few or no evidence could be found of their validity, acceptability, clinical effectiveness and cost-effectiveness in perinatal women [5]. There is only a recent study [61] showing that the two case-finding questions had a sensitivity of approximately $95 \%$ and a specificity of approximately $70 \%$, both in pregnancy and postpartum. Among women who screened positive antenatally, the third question about the need for help had a sensitivity of $58 \%$ and a specificity of $90 \%$, with lower sensitivity and higher specificity postnatally. The authors concluded that negative responses to both of the case-finding questions showed acceptable accuracy for ruling out perinatal depression and that for positive respons- es, the use of a third question about the need for help, improved specificity and the ability to rule in depression.

The Postpartum Depression Screening Scale (PDSS) [62] was developed to overcome those and other methodological limitations of the EPDS and of other instruments widely used to screen for PPD, namely the Beck Depression Inventory-I [63] and II [64]. In comparison with these instruments, PDSS achieved the best combination of sensitivity and specificity in screening for PPD [65]. The sound psychometric and operative characteristics of PDSS have been corroborated by other versions, such as the Spanish (for Hispanic women in the US) [66], the Thai [67], the Brazilian [68], and the Turkish [69]. The Portuguese PDSS version has recently proved to be valid not only for the postpartum [70], but also for pregnancy, by slightly adapting eight of its 35 items [71]. The limitation that is most commonly attributed to the PDSS is its length [5]. Meanwhile this has been overcome by the development of PDSS short versions.

Beck and Gable [62] developed a short form version (PDSS-SF) that consists of seven items, each one representing a dimension evaluated by the PDSS. PDSS-SF demonstrated equal levels of reliability and validity as the 35-item PDSS with the advantage of being completed in as little as 1-2 minutes. Other short versions composed by seven items have demonstrated their accuracy in screening for postpartum depression [72, 73] and antenatal depression [74], with sensitivity, specificity, and predictive power only slightly lower than the 35 -items version. Recently, other short versions have been developed, to use both at pregnancy and at the postpartum [75]. The criterion to select the items from the Portuguese version of the PDSS consisted of retaining those that showed strong factor loadings $(>0.60)$, which resulted in 21 items in the postpartum and in 24 items in pregnancy. The PDSS-21 and the PDSS-24 proved to be very similar or even superior to the 35-items PDSS in reliability and screening ability, which led the authors to consider them good alternatives (equally valid, but more economic, faster and easier to complete) to screen for perinatal depression.

\section{Seventh}

The acceptability of routine screening with self-report instruments from both women and health professionals, equally at postpartum and at pregnancy [5].

\section{Eighth}

The increase in recognition, diagnosis, and treatment rates, more-than-doubling the detection rate in comparison with routine practice, in the PPT $[44,76,77]$ and in pregnancy $[78,79)]$. In fact, there is evidence that if screening is combined with a subsequent intervention it may decrease depressive symptoms in the perinatal period (eg. [80]).

A recent cluster randomized trial [81], which included family medicine practice sites from around the US, compared a condition that included a regimen of screening, 
further assessment, medication management or referral, and follow-up to a usual care condition for women who scored at least 10 on the EPDS and later at least 10 on the Patient Health Questionnaire-9 [82]. More than 2000 women were enrolled between 5 and 12 weeks postpartum. A positive outcome was defined as a five-point drop on the Patient Health Questionnaire-9 at 6 and 12 months postpartum. Although there was only a trend-level effect $(p=0.007)$ at six months, there was a significant effect in favor of the intervention at 12 months. The authors attributed their success to the fact that depression was assessed in a two-stage process through self-report and because medication management was done within primary care practices. This trial demonstrated the potential of undertaking screening and of follow-up care for PPD in family medicine, a context in which women have an ongoing relationship with their family doctor.

\section{Ninth}

Because of the opportunity, given that there is a large number of convenient opportunities for routine screening in the perinatal period, when the contact with health professionals is much increased [83].

Unfortunately, there are still many women who do not have a primary care physician who routinely manages their care and it is common that once the postpartum check-up is completed, women will not have regular contact with a personal physician until their next pregnancy. Given this, there has been an ongoing debate about whether pediatricians can or should screen mothers for depression and facilitate treatment referrals [84]. The results of a recent study [85] were optimistic showing that both professionals and women present high rates $(>85 \%)$ of acceptability about discussing mental health topics including depression, at pediatric care visits.

\section{Tenth}

Although it is difficult to disentangle the effects of the screening component alone from interventions linked to a positive screen, there is preliminary evidence that perinatal screening using a self-report questionnaire is cost-effective [86]. Even though this topic remains controversial, there is some suggestive evidence from a review by the US Preventative Services Task Force [87, 88] that using formal methods to identify depression can become effective when they are accompanied by organizational enhancements of care, involving clinician education, support from case managers, or a collaborative care approach between specialists and primary care physicians. In fact, when the costs are primarily considered, managing false positives and adopting of a structured interview as a confirmatory test for those with a positive test, this proves to be cost saving compared to the equivalent strategy without an interview [89].

It is reasonable to say that the costs of doing this would be lesser than the indirect costs that come from long term implications of marital separation and of the social, educational and mental health difficulties of children affected by parental depression [3]. As a screening program may open areas of significant need, the alternative of not identifying distressed women also raises ethical issues. In this respect, the stigma of mental illness is of concern, but, as Buist et al. [3] say it "will not be overcome by ignoring the existence of mental illness".

\section{Conclusion}

In 1968, Wilson and Jungner [90] attempted to define the well-known screening criteria to guide the selection of conditions that would be suitable for screening, based, among other factors, on the capacity to detect the condition at an early stage and the availability of an acceptable treatment. The classic criteria still upheld today the "gold standard of screening assessment" have stood well the test of time (eg. $[91,92])$. The 10 reasons presented in this review clearly show that perinatal depression meets the criteria.

In conclusion, although there are major challenges inherent to the implementation of a screening program, we argue that the case for screening outweighs that against, mainly because of its high prevalence, deleterious effects in the entire family, and efficacious treatment options. However, it is important to perform it simultaneously with public health initiatives to reduce the stigma so enduringly affiliated to perinatal depression.

\section{Abbreviations}

AD: Antenatal depression; EPDS: Edinburgh Postpartum Depression Scale; PDSS: Postpartum Depression Screening Scale; PDSS-SF: Short version of Postpartum Depression Screening Scale; PPD: Postpartum depression; PPV: Positive predictive values

\section{Competing interests}

The authors declare no conflict of interest.

References

1. Wisner KL, Peindl KS, Gigliotti T, Hanusa BH. Obsessions and compulsions in women with postpartum depression. J Clin Psychiatry 1999; 60:176-180.

2. Boyce P, Bell C. Two Bites of the Chery: One Solution? In: Henshaw C, Elliot S, eds. Screening for Perinatal Depression. London and Philadelphia: Jessica Kingsley Publishers 2005; p.52-57.

3. Buist AE, Barnett BE, Milgrom J, Pope S, Condon JT et al. To screen or not to screen-that is the question in perinatal depression. Med J Austr 2002; 7(177 Suppl): S101-5.

4. O'Hara MW, McCabe JE. Postpartum depression: current status and future directions. Annu Rev Clin Psychol 2013; 28:379-407.

5. Hewitt C, Gilbody S, Brealey S, Paulden M, Palmer S et al. Methods to identify postnatal depression in primary care: an integrated evidence synthesis and value of information analysis. Health Technol Assess 2009; 13:147-230.

6. Eberhard-Gran M, Tambs K, Opjordsmoen S, Skrondal A, Eskild A. Depression during pregnancy and after delivery: a repeated measurement study. J Psychosoma Obstet Gynaecol 2004; 25:15-21.

7. Johanson R, Chapman G, Murray D, Johnson I, Cox J. The North 
Staffordshire Maternity Hospital prospective study of pregnancy-associated depression. J P Obstet Gynecol 2000; 21:93-97.

8. Marques M, Bos S, Soares MJ, Maia B, Pereira AT et al. Is insomnia a risk factor postpartum depression? Psychiatr Res 2011; 186:272-80.

9. Gaynes BN, Gavin N, Meltzer-Brody S, Lohr KN, Swinson T et al. Perinatal Depression: Prevalence, Screening Accuracy, and Screening Outcomes. Evidence Report/Technology Assessment 2005; 119.

10. Maia BR, Macedo A, Pereira AT, Marques M, Bos S et al. The Role of Perfectionism in Perinatal Depressive Disorder (ICD-10/DSMIV) and Symptomatology (BDI-II/PDSS). Arch Womens Ment Health 2012; 15:459-68.

11. Cox JL, Murray D, Chapman G. A controlled study of the onset, duration and prevalence of Postnatal Depression. Br J Psychiatry 1993; 163:27-31.

12. Cohen LS, Altshuler LL, Harlow BL, Nonacs R, Newport DJ et al. Relapse of major depression during pregnancy in women who maintain or discontinue antidepressant medication. J Am Med Association 2006; 295:499-507.

13. Zuckerman B, Amaro H, Bauchner H, Cabral H. Depressive symptoms during pregnancy: relationship to poor health behaviors. Am J Obstet Gynecol 1989; 160:1107-1111.

14. Nakano Y, Oshima M, Sugiura-Ogasama M, Aoki K, Kitamura T, Furukawa TA. Psychosocial predictors of successful delivery after unexplained recurrent abortions: a cohort study. Acta Psychiatr Scand 2004; 109:440-446.

15. Kurki T, Hiilesmaa V, Raitasalo R, Mattila H, Ylikorkala O. Depression and anxiety in early pregnancy and risk for preeclampsia. Obstet Gynecol 2000; 95:487-490.

16. Andersson L, Sundström-Poromaa I, Wulff M, Åström M, Bixo M. Implications of antenatal depression and anxiety for obstetric outcome. Obstet Gynecol 2004; 104:467-476.

17. Glover V, Bergman K, O'Connor TG. The Effects of Maternal Stress, Anxiety, and Depression During Pregnancy on the Neurodevelopment of the Child. In S Dowd Stone, AE Menken, eds. Perinatal and Postpartum Mood Disorders: Perspectives and Treatment Guide for the Health Care Practitioner. New York: Springer Company. 2008; p. 3-16.

18. Austin MP, Hadzi-Pavlovic D, Leader L, Saint K, Parker G. Maternal anxiety, depression, cognitive style and life event stress in pregnancy: relationship with infant temperament. Early Hum Dev 2005; 81:183-190.

19. Federenko IS, Wadhwa PD. Women's mental health during pregnancy influences fetal and infant developmental and health outcomes. CNS Spect 2004; 9:198-206.

20. Goodman SH, Rouse MH, Connell AM, Broth MR, Hall CM, Heyward D. Maternal depression and child psychopathology: a meta-analytic review. Clin. Child Fam Psychol Rev 2011; 14:1-27.

21. O'Connor TG, Heron J, Golding J, Glover V, ALSPAC Study Team. Maternal antenatal anxiety and behavioural / emotional problems in children: a test of a programming hypothesis. J Child Psychol Psychiatr 2003; 44:1025-1036.

22. O'Connor TG, Caprariello P, Blackmore ER, Gregory AM, Glover $\mathrm{V}$ et al. Prenatal mood disturbance predicts sleep problems in infancy and toddlerhood. Early Hum Develop 2007; 83:451-458.

23. Maki P, Veijola J, Rasanen P, Joukamaa M, Valonen P et al. Criminality in the offspring of antenatally depressed mothers: a 33-year follow-up of the Northern Finland 1966 birth cohort. J Affect Disord 2003; 74:273-278.

24. Pawlby S, Hay DF, Sharp D, Waters CS, O'Keane V. Antenatal depression predicts depression in adolescent offspring: prospective longitudinal community-based study. J Affect Disord 2008; 113:236-43.

25. Burke $L$. The impact of maternal depression on familial relationships. Int Rev Psychiatry 2003; 15:243-255.

26. Righetti-Veltema M, Conne-Perréard E, Bousquet A, \& Manzano J.
Postpartum depression and mother-infant relationship at 3 months old. J Affect Disord 2002; 70:291-306.

27. Field T. Postpartum depression effects on early interactions, parenting, and safety practices: a review. Infant Behav Dev 2010; 33:1-6.

28. Murray L, Cooper P. Postpartum depression and child development. Psychol Med 1997; 27:253-260.

29. Hay DF, Pawlby S, Sharp D, Asten P, Mills A et al. Intellectual problems shown by 11-year-old children whose mothers had postnatal depression. J Child Psychol Psychiatr 2001; 42:871-889.

30. Pawlby S, Sharp D, Hay D, O'Keane V. Postnatal depression and child outcome at 11 years: the importance of accurate diagnosis. J Affect Disord 2008; 107:241-245.

31. Dietz LJ, Jennings KD, Kelley SA, Marshal M. Maternal depression, paternal psychopathology, and disorder on child development. Is maternal preoccupation one of the key underlying processes? Dev Psychopathol 2009; 21:207-25.

32. Flykt M, Kanninen K, Sinkkonen J, Punamaki R. Maternal depression and dyadic interaction: the role of maternal attachment style. Infant and Child Development 2010; 19:530-550.

33. Stein A, Lehtonen A, Harvey AG, Nicol-Harper R, Craske M. The influence of postnatal psychiatric disorder on child development. Is maternal preoccupation one of the key underlying processes? Psychopathology 2009; 42:11-21.

34. Zajicek-Farber M. Postnatal depression and infant health practices among high-risk women. J Child Fam Stud 2009; 18:236-245.

35. Avan B, Richter LM, Ramchandani PG, Norris SA, Stein A. Maternal postnatal depression and children's growth and behaviour during the early years of life: exploring the interaction between physical and mental health. Arch Dis Child 2010; 95:690-5.

36. Murray L, Arteche A, Fearon P, Halligan S, Goodyer I, Cooper P. Maternal postnatal depression and the development of depression in offspring up to 16 years of age. J Am Acad Child Adolesc Psychiatry 2011; 50:460-70.

37. Brand SR, Brennan PA. Impact of antenatal and postpartum maternal mental illness: how are the children? Clin Obstet Gynecol 2009; 52:441-55.

38. Grace SL, Evindar A, Stewart DE. The effect of postpartum depression on child cognitive development and behavior: a review and critical analysis of the literature. Archives of Women's Mental Health 2003; 6:263-74.

39. Sohr-Preston SL, Scaramella LV. Implications of timing of maternal depressive symptoms for early cognitive and language development. Clin Child Fam Psychol Rev 2006; 9:65-83.

40. Gump BB, Reihman J, Stewart P, Lonky E, Darvill T. Trajectories of maternal depressive symptoms over her child's life span: relation to adrenocortical, cardiovascular, and emotional functioning in children. Dev Psychopathol 2009; 21:207-25.

41. Avan B, Richter LM, Ramchandani PG, Norris SA, Stein A. Maternal postnatal depression and children's growth and behaviour during the early years of life: exploring the interaction between physical and mental health. Arch Dis Child 2010; 95:690-5.

42. Ertel KA, Koenen KC, Rich-Edwards JW, Gillman MW. Antenatal and postpartum depressive symptoms. Fam Stud 2010; 18:236-45.

43. Gress-Smith JL, Luecken LJ, Lemery-Chalfant K, Howe R. Postpartum depression prevalence and impact on infant health, weight, and sleep in low-income and ethnic minority women and infants. Matern Child Health J 2012; 16:887-93.

44. Georgiopoulos AM, Bryan TL, Wollan P, Yawn BP et al. Routine screening for postpartum depression. J Fam Pract 2001; 34:117-122.

45. Hearn G, Iliff A, Jones I, Kirby A, Ormiston P et al. Postnatal depression in the community. Brit J Gen Pract 1998; 48:1064-1066.

46. Lee DTS, Chung TKH. Screening in developing countries. In C Henshaw \& S Elliot, eds. Screening for perinatal depression. London: Jessica Kingsley Publishers. 2005. p. 90-98. 
47. Flynn HA, Henshaw E, O'Mahen H, Forman J. Patient perspectives on improving the depression referral processes in obstetrics settings: a qualitative study. Gen Hosp Psychiatry 2010; 32:9-16.

48. Buist A. Perinatal depression-assessment and management. Austr Fam Physician 2006; 35:670-673.

49. Liberto TL. Screening for depression and help-seeking in postpartum women during well-baby pediatric visits: an integrated review. J Pediatr Health Care 2012; 26:109-17.

50. Goodman JH. Women's attitudes, preferences, and perceived barriers to treatment for perinatal depression. Birth: Issues in Perinatal Care 2009; 36:60-69.

51. Olson AL, Kemper KJ, Kelleher KJ, Hammond CS, Zuckerman BS, Dietrich AJ. Primary care pediatricians' roles and perceived responsibilities in the identification and management of maternal depression. Pediatrics 2002; 110:1169-1176.

52. Wiley CC, Burke GS, Gill PA, Law NE. Pediatricians' views of postpartum depression: a self-administered survey. Arch Wom Menl Health 2004; 7:231-236.

53. Whitton A, Appleby L, Warner R. The pathway to care in post-natal depression: women's attitudes to post-natal depression and its treatment. Brit J Gen Pract 1996; 46:427-428.

54. Pereira AT, Marques M, Soares MJ, Maia BR, Bos S, Valente J, Nogueira V, Roque C, Madeira N, Macedo A. Profile of depressive symptoms in women in the perinatal and outside the perinatal period: similar or not? Journal of Affective Disorders 2014; 166:71-78.

55. Cox J, Holden J, Sagovsky R. Detection of post natal depression. Development of the 10 items EPDS. Br J Psychiatry 1987; 150:782-786.

56. Riecher-Rossler A. Prospects for the classification of mental disorders in women. Eur Psychiatry 2010; 25:189-96.

57. Bernstein IH, Rush AJ, Yonkers K, Carmody TJ, Woo A et al. Symptom features of postpartum depression: are they distinct? Dep Anx 2008; 25:20-26.

58. Wisner KL, Chambers C, Sit DK. Postpartum depression: a major public health problem. J Am Med Assoc 2006; 296:2616-2618.

59. Gibson J, McKenzie-McHarg K, Shakespeare J, Price J, Gray R. A systematic review of studies validating the Edinburgh Postnatal Depression Scale in antepartum and postpartum women. Acta Psychiat Scand 2009; 119:350-64.

60. NICE. Antenatal and postnatal mental health: clinical management and service guidance. 2007.

61. Mann R, Adamson J, Gilbody SM. Diagnostic accuracy of case-finding questions to identify perinatal depression. CMAJ 2012; 184:E424-30.

62. Beck CT, Gable RK. Postpartum Depression Screening Scale manual. Los Angeles: Western Psychological Services. 2002.

63. Beck AT, Steer RA. Manual for the Beck Depression Inventory-II San Antonio, TX: Psychological Corporation. 1996.

64. Ban L, Gibson JE, West J, Tata LJ. Association between perinatal depression in mothers and the risk of childhood infections in offspring: a population-based cohort study. BMC Public Health 2010; 31:10-20.

65. Beck CT, Gable RK. Comparative analysis of the performance of the Postpartum Depression Screening Scale with two other depression instruments. Nur Res 2001; 50:242-250.

66. Beck CT, Gable RK. Postpartum Depression Screening Scale Spanish version. Nur Res 2003; 52:296-306.

67. Vittayanont A, Liabsuetrakul T, Pitanupong J. Development of Postpartum Depression Screening Scale (PDSS): a Thai version for screening postpartum depression. J Med Assoc Thai 2006; 89:1-7.

68. Cantilino A, Carvalho JA, Maia A, Albuquerque C, Cantilino G, Sougey EB. Translation, validation and cultural aspects of postpartum depression screening scale in Brazilian Portuguese. Transcult Psychiatry 2007; 44:672-684.
69. Karaçam Z, Kitis Y. The Postpartum depression Screening Scale: Its Reliability and Validity for Turkish Population. Turk Psikiyatri Dergisi 2007; 18:1-13.

70. Pereira AT, Bos S, Marques M, Maia BR, Soares MJ et al. The Portuguese version of the Postpartum Depression Screening Scale. J P Obstet Ginecol 2010; 31:90-100.

71. Pereira AT, Bos SC, Marques M, Maia B, Soares MJ et al. The Portuguese version of the Postpartum Depression Screening Scale - Is it valid to screen for antenatal depression? Arch Wom Ment Health $2011 ; 14: 227-38$

72. Zubaran C, Schumacher MV, Foresti K, Thorell MR, Amoretti A et al. The Portuguese version of the Postpartum Depression Screening Scale-Short Form. J Obstet Gynaecol Res 2010; 36:950-7.

73. Pereira AT, Bos S, Maia BR, Marques M, Soares MJ et al. The Portuguese short version of the Postpartum Depression Screening Scale. Eur Psych 2011; 26(Suppl. 1 P03-507).

74. Pereira AT, Bos S, Maia BR, Marques M, Soares MJ et al. Development and validation of the Portuguese short version of the Postpartum Depression Screening Scale to screen for antenatal depression. Eur Psych 2012; 27(Suppl. 1, P-1476).

75. Pereira AT, Bos S, Maia BR, Marques M, Soares MJ et al. Short forms of the postpartum depression screening scale: as accurate as the original form. Arch Wom Ment Health 2013; 16:67-77.

76. Evins GC, Theofrastous JP, \& Galvin SL. Postpartum depression: A comparison of clinical and routine clinical evaluation. American Journal of Obstetrics and Gynecology 2000; 182:1080-1082.

77. Fergerson SS, Jamieson DJ, Lindsay M. Diagnosing postpartum depression: can we do better? Am J Obstet Gynecol 2002; 186:899-902.

78. Elliott SA, Leverton TJ, Sanjack M, Turner H, Cowmeadow P et al. Promoting mental health after childbirth: A controlled trial of primary prevention of postnatal depression. Br J Clin Psych 2000; 39:223-241.

79.Zlotnick C, Miller IW, Pearlstein T, Howard M, Sweeney P. A preventive intervention for pregnant women on public assistance at risk for postpartum depression. Am J Psych 2006; 163(8):1443-1445.

80. Dennis CL, Hodnett E. Psychosocial and psychological interventions for treating postpartum depression. Cochrane Database of Systematic Reviews 2007; 4:CD006116.

81. Yawn B, Dietrich AJ, Wollan P, Bertram S, Graham D et al. TRIPPD: a practice-based effectiveness study of postpartum depression screening and management. Ann Fam Med 2012; 10:320-29

82. Spitzer RL, Kroenke K, Williams JB. Validation and utility of a self-report version of PRIME-MD: the PHQ primary care study. Primary Care Evaluation of Mental Disorders. Patient Health Questionnaire. JAMA 1999; 282:1737-44.

83. Gjerdingen DK, Yawn BP. Postpartum depression screening: importance, methods, barriers, and recommendations for practice. J Am Board Fam Med 2007; 20:280-288.

84. Chaudron LH, Szilagyi PG, Kitzman HJ, Wadkins HI, Conwell Y. Detection of postpartum depressive symptoms by screening at wellchild visits. Pediatrics 2004; 113:551-8.

85. Walker LO, Im EO, Tyler DO. Maternal Health Needs and Interest in Screening for Depression and Health Behaviors During Pediatric Visits. J Pediatr Health Care 2013; 27(4):267-77.

86. Hewitt CE, Gilbody SM. Is it clinically and cost effective to screen for postnatal depression: a systematic review of controlled clinical trials and economic evidence. BJOG 2009; 116:1019-27.

87. Pignone MP, Gaynes BN, Rushton JL, Burchell CM, Orleans CT et al. Screening for depression in adults: a summary of the evidence for the U.S. Preventive Services Task Force. Annals Int Med 2002; 136:765-76.

88. Gilbody S, Whitty P, Grimshaw J, Thomas R. Educational and organizational interventions to improve the management of depression in primary care: a systematic review. JAMA 2003; 289:3145-51. 
89. Paulden M, Palmer S, Hewitt C, Gilbody S. Screening for postnatal depression in primary care: cost effectiveness analysis. BMJ 2009; 339:b5203.

90. Wilson JM, Jungner YG. Principles and practice of mass screening for disease. Bol Oficina Sanit Panam 1968; 65:281-393.
91. Hall DM, Stewart-Brown S. Screening in child health. Br Med Bull 1998; 54:929-43.

92. Linnane E, Paul A, Parry R. Screening of newborn infants for cholestatic hepatobiliary disease. Does test fulfil screening criteria? BMJ 1999; 319:1435. 